\title{
NARRATIVA E IDENTIDADE NO MST
}

\author{
Vanderlei J. Zacchi ${ }^{1}$
}

vanderlei@ufs.br

RESUMO: O papel da narrativa na construção da identidade do semterra é o tema central deste trabalho. O processo de narrar envolve a possibilidade de se construir uma identidade para si mesmo. No caso do MST, esse é um artificio importante para que o movimento apresente tanto para os próprios sem-terra quanto para a sociedade como um todo - uma imagem diferente daquela que é proposta, e às vezes imposta, por grupos dominantes, normalmente identificados como seus adversários. Trata-se de instituir contra-narrativas que vāo nortear não apenas a autorepresentaçāo. mas também as açōes dos sem-terra. Ao fazê-lo, a identidade que o movimento busca construir tanto pode assentar-se sobre atributos retirados da tradição - e reforçar, portanto, tendências puristas quanto instituir a diferença como um de seus elementos fundamentais. Parte importante dessa análise é a postura que o movimento assume em relação a manifestações linguisticas e culturais com base em textos retirados de suas midias virtuais e impressas.

Palavras-chave: narrativa; identidade; estrangeirismos; cultura

\section{INTRODUÇĀO}

Um dos principais objetivos do Movimento dos Trabalhadores Rurais Sem Terra (MST) é assegurar que se realize no Brasil uma ampla reforma agrária que garanta o acesso à terra a milhões de trabalhadores do campo, atualmente às margens do processo produtivo. Para o movimento, no entan-

1 Professor da Universidade Federal de Sergipe 
to, o acesso à terra não seria suficiente, pois não mudaria a estrutura social vigente e manteria as condições que têm gerado a desigualdade no campo no decorrer da história. Para alcançar esses objetivos, o MST tem-se aliado a grupos sociais diversificados, que podem agir tanto local quanto globalmente. São grupos que não têm necessariamente as mesmas causas que o movimento, como reforma agrária ou financiamento agrícola, mas que têm em comum com o MST a condição de serem grupos minoritários de resistência aos interesses dos grupos dominantes e hegemônicos. Na pauta do movimento, portanto, entram também questões como diferenças de classe, gênero e etnia, ou ainda aquelas relacionadas ao ambientalismo. Todos esses aspectos pressupõem alguma forma de negociação e articulação, gerando conflitos e contradições que são extremamente importantes para a construção da identidade do movimento.

Marina dos Santos (2006), integrante da Coordenação Nacional do MST, afirma em entrevista que "O principal inimigo do MST é o avanço da parceria entre latifúndio, o agronegócio e empresas transnacionais da agricultura" Por trás dessa parceria, no entanto, estão categorias mais amplas: o neoliberalismo, as grandes potências - os Estados Unidos em especial, pelo seu papel de liderança - e a chamada grande mídia. Em oposição a essas forças, o movimento busca afirmar sua identidade. Segundo Gohn (2006, p. 10), o MST se formou ao redor de uma identidade, a do sem-terra, que tem a perspectiva de alterar a qualidade dessa identidade e passar a ser um "com-terra" Nesse processo, o objetivo não é alcançado apenas com a conquista do titulo da propriedade ou do crédito necessário para trabalhar a terra, mas com a transformação de toda a sociedade. A auto-representação da identidade do grupo deixa entrever o grau de abrangência do movimento, que elege como adversários atores de tão grande porte e alcance.

Marina dos Santos aponta ainda outro inimigo do MST e da sociedade brasileira: a falta de um projeto para o Brasil. 
Um novo modelo agricola precisa de um projeto de desenvolvimento nacional, que tenha como centro o fortalecimento do mercado interno, a distribuição de renda, a indústria nacional para sustentar a geração de emprego e renda para o povo. $O$ MST está fazendo o seu papel com suas mobilizações populares, nos debates com a sociedade e na formulação desse projeto de desenvolvimento nacional. (SANTOS, 2006 - grifos meus).

A insistência da agricultora num plano de desenvolvimento nacional remete-nos a mais um aspecto identitário do grupo: o movimento se assenta sobre um projeto de nação, que ele pretende que seja estendido a toda a sociedade brasileira. Essa ideia está implícita no slogan do movimento entre 1995 e 2000: "Reforma agrária: uma luta de todos!" (HISTORY..., 2006). Para Marina, "As terras devem estar a serviço do povo brasileiro" e não para atender às necessidades das transnacionais da agricultura e do mercado financeiro internacional.

Seria o caso de se questionar se a identidade que o MST busca construir para si não estaria baseada num ideário de nação brasileira inspirado por noções essencialistas de cultura. O que faria supor que o termo "brasileiro" é mais bem caracterizado por um certo povo e uma certa cultura, considerados legítimos pelo movimento e que seriam a base de resistência à invasão externa representada pelo neoliberalismo e as empresas transnacionais. Os setores brasileiros que se alinham com o capital internacional - como o agronegócio, o latifúndio, as elites e a grande mídia - não estariam defendendo os interesses da nação.

Uma leitura mais atenta, no entanto, pode apontar outros caminhos. Em primeiro lugar, as identidades do MST não se limitam apenas a uma afirmação do seu caráter nacional. Em oposição às transnacionais da agricultura, por exemplo, o movimento se alinha com grupos ambientalistas internacionais, defendendo um desenvolvimento sustentado e a preservação do meio ambiente, como ocorre na campanha contra a liberação do plantio de milho transgênico no Brasil, 
da qual participa, entre outros, o Greenpeace. Há também um forte interesse em combater a desigualdade de relação entre homens e mulheres, tanto dentro quanto fora do movimento, fazendo par com interesses históricos de movimentos feministas em várias partes do mundo. Para Lourdes Vicente, integrante do Setor de Gênero, que foi instituído em 2000 (MULHER..., 2006), a mulher sem-terra é duplamente oprimida: pela exploraçāo do capital e por ser mulher. Mas, na comparação com as mulheres do campo em geral, as do movimento apresentam um diferencial. Lourdes Vicente acredita que "as sem-terra têm uma chance de se reconhecerem oprimidas e de construírem uma identidade com a discussāo de seu papel social, questionando e problematizando"

Outro aspecto que entra em conflito com o discurso nacionalista do movimento é o fato de que, para que seja possivel o intercâmbio com grupos internacionais e, principalmente, com aqueles que defendem interesses mais intimamente relacionados ao movimento - como reforma agrária, financiamento agricola e soberania alimentar -, o MST faz uso de duas importantes ferramentas: linguas estrangeiras, notadamente o inglês, e novas tecnologias de comunicação, como a Internet. Lançada em 1996, a página www.mst.org.br recebe cerca de 1.000 visitas por dia, segundo o próprio movimento (COMMUNICATIONS..., 2006).

Os conflitos presentes na auto-representação e nas açōes do movimento definem o contexto para a discussão a seguir, concentrada no papel desempenhado pela narrativa na construção da identidade do sem-terra. A partir da ideia de que o direito de narrar pressupõe o direito de se construir uma identidade para si mesmo (BHABHA, 2003), chega-se às definições de identidade de tradução e de tradição (HALL, 2003), que serão então trabalhadas com base nas concepções de linguagem e de cultura do movimento. 


\section{NARRATIVA}

A tentativa de construção de uma identidade nacional, por um lado, e a cooperaçāo com outros agentes nacionais e internacionais, por outro, podem configurar-se como fonte de conflitos para o movimento. Mais ainda se levarmos em consideração que essa cooperação se dá através de ferramentas que têm como grande centro irradiador os Estados Unidos, pais de onde também se originam, em boa parte, os adversários do MST. Conflito e contradição são inerentes à constituição da identidade de um movimento social:

No que diz respeito a atores sociais, entendo por identidade o processo de construçāo de significado com base em um atributo cultural, ou ainda um conjunto de atributos culturais inter-relacionados, o(s) qual(ais) prevalece(m) sobre outras fontes de significado. Para um determinado individuo ou ainda um ator coletivo, pode haver identidades múltiplas. No entanto, essa pluralidade é fonte de tensão e contradição tanto na auto-representação quanto na açāo social. (CASTELLS, 1999b, p. 22)

No MST, a auto-representação ("sem-terra") é usada justamente para reforçar a ideia de que a ação social é necessária: ${ }^{2}$

Muitas pessoas que ouvem falar nos "Sem Terra" imaginam que somos trabalhadores rurais, meeiros ou arrendatários que nāo possuem terra. / "Sem-Terra" se tornou um nome próprio - o nome dos trabalhadores que se organizaram para lutar pela Reforma Agrária e pela transformação da sociedade. / "Sem-Terra" se tornou um símbolo para o resgate da dignidade de trabalhadores e trabalhadoras que antes eram chamados de andarilhos, chutados de um lado para o outro. Esses trabalhadores alcançaram sua própria identidade ao se juntar à luta: Eu sou um "Sem-Terra" é afirmado com orgulho. (WHO..., 2006)

2 A tradução dos textos originalmente em lingua estrangeira foi efetuada pelo próprio autor deste trabalho. 
Para o MST portanto, a identidade se constroi na própria luta e se faz a partir da contraposição a uma narrativa concebida por terceiros, conforme se verá abaixo. Para Castells (1999b), toda identidade é construída a partir de elementos fornecidos pelas mais variadas fontes: história, biologia, memória coletiva, aparatos de poder e outros. Caberia aos grupos sociais, segundo o autor, processar todo esse material e reorganizar seu significado "em função de tendências sociais e projetos culturais enraizados em sua estrutura social" (p. 23), ideia que remete à noção de orquestração de discursos de Bakhtin (1988, p. 146): "Nossa transformaçāo ideológica é justamente um conflito tenso no nosso interior pela supremacia dos diferentes pontos de vista verbais e ideológicos" Para Bakhtin, a autoria do discurso se dá através das vozes às quais o falante está exposto. Elas somente se tornam "próprias" quando ele "als] povoa com sua intenção, com seu acento" (p. 100). Tomando as palavras de outros, o sujeito as reelabora internamente, tornando-as parcialmente suas, num processo dialógico com outros discursos com os quais esteve em contato em outros momentos, para em seguida torná-las palavras próprias. Bakhtin mostra que o discurso interno, sendo aberto e inacabado, está sujeito às relações sociais e condiçōes materiais em que está inserido. Ele está em constante diálogo com seu meio e em relação com outros discursos.

Bruner (1990, p. 137) trabalha com uma concepção semelhante no que ele chama de "psicologia popular" (folk psychology): "noçōes culturalmente delimitadas segundo as quais as pessoas organizam os pontos de vista que têm de si mesmas, dos outros e do mundo em que vivem" É, portanto, um processo baseado na construção de sentido:

... as vidas e os Eus (Selves) que construimos são o resultado desse processo de construção de sentido. Mas [...] os Eus não são núcleos isolados de consciēncia encerrados na cabeça, mas sāo "distribuidos" interpessoalmente. Nem tampouco os Eus surgem desenraizadamente em resposta apenas ao presente; eles obtêm sentido também das cir- 
cunstâncias históricas que deram forma à cultura da qual eles sāo uma expressāo. (BRUNER, 1990, p. 138)

Substituindo-se o termo "Eu" por "identidade" temos o conceito de identidade coletiva conflituosa usado neste trabalho. Pode-se dizer, assim, que a construção da identidade nos movimentos sociais - a exemplo da autoria do discurso de Bakhtin e da psicologia popular de Bruner - é um processo interno e conflituoso, mas em estreita correlação com os dados externos, que são múltiplos e variáveis, tanto no tempo quanto no espaço. A construção de sentido, para Bruner, se dá através da narrativa e da interpretaçāo. Cada cultura fornece a seus membros um estoque de narrativas, que não são fixas, pois mudam no decorrer do tempo. Um dos aspectos que definem uma narrativa é o fato de ela ser sensivel ao que é previsto (cânone) e ao que rompe com essa expectativa. Essa canonicidade também é construída e depende da interpretação. As narrativas canônicas, em geral, identificam-se com os grupos dominantes, enquanto que as minorias buscam romper com a previsibilidade por meio de suas contra-narrativas:

Uma vez adotada a ideia da narrativa, pode se perguntar por que uma história e não outra. E tal questionamento logo levou à suspeita de que as concepçōes de Eu "oficiais" ou "impostas" poderiam ser usadas para o estabelecimento de controle político ou hegemônico de um grupo sobre outro. (BRUNER, 1990, p. 114)

Quando uma narrativa toma um aspecto demasiadamente ideológico ou para atender a interesses próprios, Bruner (p. 96) afirma que há uma "superespecialização da narrativa" Como resultado, a descrença toma o lugar da interpretação e pode haver uma ruptura cultural. Para Bhabha (2003, p. 181), o que acontece nesse caso é a supressão do direito de narrar, efetivada em geral por sociedades autoritárias, paises xenófobos, Estados militares. Recorrendo-se a Gramsci (2000), pode-se 
dizer que essa situação de conquista e manutenção da hegemonia se dá através da coerção, do uso da força, em oposição à hegemonia do consenso, que pressupõe a negociação.

Conforme já se mencionou, na auto-representaçāo do MST apresentada acima (WHO..., 2006) há uma justaposição de narrativas conflituosas. A representação em torno da palavra "Sem-Terra" mostra como seu significado muda de acordo com o lócus de enunciação do narrador. Numa narrativa canônica, o termo representa pessoas desocupadas, insignificantes, "chutadas de um lado para o outro" A Uniāo Democrática Ruralista (UDR), formada por fazendeiros e latifundiários, classificou os sem-terra como "preguiçosos e vagabundos" (BOGO, 2005). Essa é a ideia subjacente ao senso comum que os grupos dominantes, adversários do MST, precisam reiterar para a manutençāo do controle. O movimento, no entanto, apropria-se desse senso comum para explicar o excepcional: "Eu sou um 'Sem-Terra' é afirmado com orgulho" explicitando ainda um outro aspecto considerado por Bruner (1990, p. 77) e fundamental na narrativa: a perspectiva do narrador. Como numa autobiografia, o discurso do MST conjuga as vozes do narrador e do protagonista.

Esse conflito de representações remete ao que Menezes de Souza (2004, p. 117), aludindo à obra de Homi Bhabha, considera "uma fenda entre o significante e o significado" Em vez de uma representação de algo exterior, ou o real, o texto entra num processo de produção de significados, estabelecendo histórica e ideologicamente posições de sujeito, que tanto podem ser do autor quanto do leitor. As "condições de existência do texto" na produção e na recepção, são constituídas nessa negociação de significados. Segundo Ricoeur (1976, p. 91), há mais de um modo de construir um texto, mas seu campo de construções possiveis é limitado. Por outro lado, há uma versatilidade maior nas possibilidades de interpretação: "É sempre possivel argumentar a favor de ou contra uma interpretação, confrontar interpretações, arbitrar entre elas e procurar um acordo" O que está por detrás do 
texto não é a intenção do autor, nem tampouco a situação histórica do autor e de seus leitores originais. A interpretação permite apropriar-se do "poder de desvelar um mundo, que constitui a referência do texto" (p. 104). Ela produz um evento do discurso, no momento presente: torna-se, portanto, um acontecimento.

A negociação de significados está no cerne também do que Bhabha chama de "direito de narrar":

...todas aquelas formas de comportamento criativo que nos permitem representar as vidas que levamos, questionar as convençōes e costumes que herdamos, contestar e propagar as ideias e ideais que chegam até nós naturalmente e ousar alimentar os mais audaciosos medos e esperanças para o futuro. (2003, p. 180)

Bhabha considera ainda que a narrativa é tanto discurso quanto ação e é o próprio meio pelo qual nos revelamos uns aos outros. O direito de narrar, portanto, tem forte correlaçāo com o direito de se construir uma identidade para si mesmo.

\section{IDENTIDADE}

Castells (1999b, p. 24) classifica as identidades coletivas em três grupos: a legitimadora, a de resistência e a de projeto. A identidade legitimadora - "introduzida pelas instituições dominantes da sociedade no intuito de expandir e racionalizar sua dominação em relação aos atores sociais" aplica-se a diversas teorias do nacionalismo. A identidade de resistência, por outro lado, está vinculada a grupos sociais em desvantagem diante da lógica da dominação e que constroem sua resistência a partir de princípios diferentes, ou mesmo opostos, aos das instituições dominantes da sociedade. O discurso nacionalista, por exemplo, foi muitas vezes defendido por essas instituições em outras épocas. Hoje ele 
foi apropriado por grupos minoritários, como os próprios semterra - que buscam um resgate do que eles entendem por cultura popular brasileira em resposta a uma lógica de dominação internacional representada principalmente pelos Estados Unidos. Nesse caso, o MST se insere na categoria de identidade de resistência.

Por não estar apenas defendendo interesses próprios, mas também propondo uma transformação da sociedade (GOHN, 2006, p. 10), o movimento se encaixa ainda na identidade de projeto: "quando os atores sociais, utilizando-se de qualquer tipo de material cultural ao seu alcance, constroem uma nova identidade capaz de redefinir sua posição na sociedade e, ao fazê-lo, de buscar a transformação de toda a estrutura social" (CASTELLS, 1999b, p. 24). Se na modernidade a identidade de projeto foi constituída na sociedade civil, na sociedade em rede atual ela se desenvolve a partir da resistência comunal. Portanto, para Castells, na era da informação, os sujeitos transformacionais são um prolongamento da resistência comunal. Mas, na sociedade em rede, as comunidades não estão isoladas. Castells (1999a, p. 498) define rede como "um conjunto de nós interconectados" de modo que a distância entre dois pontos (ou posições sociais) é menor se ambos forem nós de uma mesma rede. Estar fora da rede é estar excluido. Conforme discutido anteriormente, o direito de se construir uma identidade pode ser alcançado por meio do direito de narrar, cujo sujeito, segundo Bhabha (2001), não é o individuo, "mas toda uma rede discursiva, cultural, política, institucional, uma rede de eventos e enunciaçōes e construções e escritas que constroem a possibilidade da narração. É um direito enunciatório" Assim, o MST procura ampliar sua rede incluindo outros grupos minoritários e oprimidos, como os indios e os quilombolas, que de outra forma poderiam estar total ou parcialmente excluídos: nós fora da rede. Esses nós são semelhantes ao que Laclau (2000, p. 57) chama de "pontos nodais de articulação" a partir dos quais há uma recomposição da estrutura, a criação de novas identi- 
dades e a produção de novos sujeitos. Um exemplo dessa articulação é a campanha iniciada pelo MST - em parceria com entidades ligadas às lutas indigenas e a Via Campesina (instituição internacional que reúne diversos movimentos rurais) para recolher assinaturas em um abaixo-assinado pela demarcação, no Espirito Santo, das terras Tupiniquim e Guarani que estão sob posse da Aracruz Celulose, empresa responsável também, segundo o MST, pela expulsão de mais de oito mil famílias quilombolas no estado (CAMPANHA..., 2007).

A articulação entre o MST e outros grupos ou movimentos sociais aponta para uma coexistência plural no interior da estrutura social, mas não em uma situaçāo em que cada grupo mantém uma identidade essencial e individual, pressupondo uma convivência harmoniosa e de mútuo respeito. $\mathrm{Na}$ verdade, há momentos de intersecção entre as diversas identidades que compõem uma sociedade, que podem resultar tanto em acordos quanto em conflitos. Requerem, portanto, uma negociação e, nesse processo, a identidade de cada grupo se modifica. Para Mouffe (1995, p. 317), é um movimento de mão dupla. De um lado, há um descentramento na estrutura social que impede a fixação de posições em torno de um ponto preestabelecido. Na direção contrária, há a instituição de pontos nodais, "fixações parciais que limitam o fluxo do significado sob o significante" Essa dialética só é possivel porque não há um centro de subjetividade anterior às identificações do sujeito. O resultado é, portanto, uma "estrutura descentrada" (LACLAU, 2000, p. 56), marcada não por uma simples ausência de centro, mas por "uma pluralidade de centros de poder com diferente capacidade de irradiação e estruturação, em luta entre si" Esse deslocamento estrutural, por sua vez, implica uma atuação no mundo, que, não sendo predeterminado, precisa ser construído, de modo que, consequentemente, os agentes sociais acabam transformando também a si mesmos, e novas identidades são forjadas.

No âmbito da política, Mouffe (1995, p. 327) acredita que a transformação de subjetividades já existentes é fun- 
damental para a implantaçāo de uma democracia radical, cujo objetivo deveria ser a construção de uma identidade politica coletiva visando a uma nova hegemonia, articulada através de relações, práticas e instituiçōes sociais novas e igualitárias. Para isso, seria necessário que os movimentos sociais se organizassem em torno de causas em comum, utilizando-se do princípio da "equivalência democrática" (p. 325), sem eliminar as diferenças. O bem comum (de toda a sociedade), nesse caso, seria apenas uma referència, mas nunca poderia ser alcançado, pois uma comunidade sem conflitos e antagonismos é inimaginável. Dessa forma, a própria noçāo de "bem comum" estará também em constante transformação e negociação.

O MST, ao transcender seus objetivos corporativos (a reforma agrária), alia-se a grupos e movimentos sociais que têm causas em comum - índios, ecologistas, mulheres, desempregados, entre outros -, em especial por sofrerem algum tipo de opressão ou por resistirem ao poder dominante e suas narrativas canônicas totalizantes. O movimento adota uma estratégia identitária que lhe permite atuar em diversas frentes. Se por vezes ostenta um discurso de cunho nacionalista, também se engaja em disputas internacionais que podem estar relacionadas tanto a seus interesses imediatos quanto aos de grupos estrangeiros em situação de desvantagem, como é o caso de seu apoio à causa do Líbano e da Palestina na disputa histórica que esses paises travam com Israel. Em situaçōes como essa, a língua inglesa e a Internet são ótimas aliadas, apesar de serem instrumentos que, conforme já mencionado anteriormente, estão em grande parte identificados com paises hegemônicos, como os Estados Unidos. A questāo é que uma identidade não anula completamente a outra.

Algumas identidades gravitam ao redor daquilo que Robins chama de "Tradiçāo" tentando recuperar sua pureza anterior e recobrir as unidades e certezas que são sentidas como tendo sido perdidas. Outras aceitam que as identidades estão sujeitas ao plano da História, da Política, da represen- 
tação e da diferença e, assim, é improvável que elas sejam outra vez unitárias ou "puras"; e essas, consequentemente, gravitam ao redor daquilo que Robins (seguindo Homi Bhabha) chama de "Tradução" (HALL, 2003, p. 87)

Portanto, a afirmação da identidade do MST remete à "tradução" pois é uma identidade contingente, criada para enfrentar seus adversários históricos, e que estará em constante mudança, em função dos desenvolvimentos políticoculturais de cada época e de suas relações com outros grupos e movimentos sociais. Isso não quer dizer que, em alguns momentos, o movimento também não assuma uma identidade de "tradição" Há, no discurso do MST, uma tendência em considerar o estrangeiro como uma ameaça à "pureza" do elemento nacional. Mesmo não sendo o nacionalismo o elemento principal que molda a identidade do sem-terra, ele está presente em seus discursos, contradizendo aspectos do movimento que lhe dão expressão mundial.

Para Hall (2003, p. 48-49), a nação é uma comunidade simbólica, um "sistema de representação cultural" que produz sentidos e consequentemente constroi identidades, ao fazer que as pessoas participem da ideia da nação como uma representação de sua cultura nacional. Um dos aspectos que colaborariam para a construção dessa identidade é a ênfase na tradição e nas origens, de modo que os elementos essenciais do caráter nacional permaneceriam imutáveis. Mas se, por um lado, o MST busca forjar uma cultura brasileira unificada, desconsiderando as diferenças, por outro defende a diversidade como forma de resistência às forças homogeneizantes da globalização. Essa contradição se explica pelo fato de que "as identidades nacionais nāo subordinam todas as outras formas de diferença e não estão livres do jogo de poder, de divisões e contradiçōes internas, de lealdades $e$ de diferenças sobrepostas" (HALL, 2003, p. 65).

De acordo com Bhabha, o que caracteriza a nação não é tanto sua individualidade em relação a outras nações, mas a heterogeneidade conflituosa de seu povo: 
Estamos diante da nação dividida no interior dela própria, articulando a heterogeneidade de sua populaçāo. A nação barrada Ela/Própria [It/Self], alienada de sua eterna autogeração, torna-se um espaço liminar de significação, que é marcado internamente pelos discursos de minorias. pelas histórias heterogêneas de povos em disputa, por autoridades antagônicas e por locais tensos de diferença cultural. (BHABHA, 1998. p. 209-210)

A nação é produzida pela cisão narrativa entre uma temporalidade continuísta, cumulativa, que representa "uma eternidade produzida por autogeração" (p. 209) - o pedagógico - e uma estratégia repetitiva, recorrente, " $a$ interpelação mais específica a interesses e identidades contenciosos, desiguais, no interior de uma população" (p. 207) - o performativo. O povo, nesse caso, não é nem o princípio nem o fim da narrativa nacional: ele representa o tênue limite entre o pedagógico e o "performativo" Mas é o "performativo" que intervém na soberania da autogeração da nação e introduz "a temporalidade do entrelugar" (p. 209), evitando a polaridade entre a nação e seus outros externos e reiterando as "fraturas e ausências" (p. 235) da história nacional: no caso do Brasil, o índio, o negro, o caboclo, o sem-terra.

Patton (1995, p. 227) argumenta que, por atuarem necessariamente num contexto, as identidades são elas próprias "performativas" A "performatividade" segundo Yúdice (2004, p. 74-75), baseia-se na ideia de que a reprodução de hierarquias sociais é obtida pela repetição de normas. Mas, como a repetiçāo nunca é exata, existe sempre uma discrepância, gerando a mudança. Nesse processo, muitas mudanças acabam por ser incorporadas à estrutura social, abrindo espaço para novas transformaçōes. Bruner (1990, p. 47) afirma que a negociação de sentidos essencial para uma cultura depende da capacidade da narrativa de lidar com o cânone e o excepcional ao mesmo tempo. Se uma cultura contém um conjunto de normas, ela deve conter também um conjunto de 
procedimentos interpretativos para dar sentido à exceção. " $A$ função da narrativa é encontrar um estado intencional que atenue ou pelo menos torne compreensivel um desvio de um padrão cultural canônico. É esse o feito que dá verossimilhança a uma história. Pode the dar também uma função apaziguadora" diz Bruner (p. 49-50 - grifos no original). As narrativas e suas interpretações estão no centro dos conflitos entre grupos sociais diversos: para os dominantes, como forma de neutralizar a exceção ou incorporá-la à regra; para os oprimidos, como uma maneira de reiterar as diferenças e relativizar a posição do dominante.

Segundo Bhabha, na leitura entre as fronteiras do espaço-nação, há um movimento narrativo duplo na concepçāo de povo: "Os fragmentos, retalhos e restos da vida cotidiana devem ser repetidamente transformados nos signos de uma cultura nacional coerente, enquanto o próprio ato da "performance" narrativa interpela um círculo crescente de sujeitos nacionais" (1998, p. 207). Para ele, é nesse conflito que se dá a escrita da nação. E são as "contra-narrativas" (p. $211)$ da nação que transgridem suas fronteiras totalizadoras e impedem as identidades essencialistas. Esse conflito também está presente na atuação do MST que faz uso de contranarrativas (a exceção ao cânone) para afirmar a(s) diferença(s), não só do próprio grupo como também de outras minorias. No entanto, ao evocar uma identidade nacionalista, como algo inerente e nāo construído, o movimento faz uso de uma narrativa canônica em muitos casos utilizada também por instituições conservadoras e tradicionalistas, mais bem caracterizadas pela identidade legitimadora - por buscar "expandir e racionalizar sua dominação em relação aos atores sociais" (CASTELLS, 1999b, p. 24) - ou de tradição, por tentar "recobrir as unidades e certezas que são sentidas como tendo sido perdidas" (HALL, 2003, p. 87). 


\section{TradiçĀo ou traduÇão?}

Entre os adversários do MST, estão empresas transnacionais que desenvolvem produtos geneticamente modificados e outras responsáveis pelos chamados desertos verdes, que são enormes áreas de monocultivo de eucalipto. No caso destas últimas, as consequências podem ser múltiplas e duradouras. No âmbito ecológico e agrário, ocorrem a desertificação e a diminuição da biodiversidade. No âmbito econômico e sociocultural, a monocultura de eucalipto pode causar a especialização da atividade de produção, gerando a ruptura de tradições produtivas, como a pecuária e a agricultura de subsistência, que é realizada nos espaços que separam as grandes propriedades. A transformação da paisagem e da identidade cultural é também outro efeito:

As áreas onde há monocultura de eucalipto, como a região dos campos do Rio Grande do Sul, são ecossistemas em risco. O lugar faz parte da construção da identidade das pessoas e sua modificação, com a plantação das mesmas árvores, quilōmetros a fio, implica uma transformaçāo violenta da cultura local. (EUCALIPTO..., 2006, p. 21)

Em oposição às monoculturas introduzidas pelas transnacionais, o MST vem desenvolvendo técnicas inovadoras na agricultura, como produtos orgânicos e sementes livres de agrotóxicos. Noutros âmbitos, porém, a ameaça externa pode ter implicações diferentes, principalmente no que se refere a manifestações artístico-culturais e linguísticas. No aspecto linguístico, a página oficial do movimento na Internet não contém qualquer estrangeirismo, mesmo aqueles típicos do mundo eletrônico virtual, que obviamente se originam do inglês. O site está disponivel em sete línguas estrangeiras, mas a página em português está livre de estrangeirismos, mantendo-se pretensamente pura e sem a possibilidade de interação com as demais linguas. 
Tanto no caso da língua como no de outras expressões culturais, a ameaça em geral está representada pelo mundo anglo-americano. Na música, é o estilo country, "com suas roupas de cowboy e músicas pasteurizadas no estilo dos grandes rodeios" segundo reportagem do Jornal Sem Terra (VIOLAR..., 2006, p. 10). Edvar Lavratti, da direção estadual do MST em São Paulo, afirma: "Nada disso é nosso" Diante dessa constatação, os sem-terra decidiram criar, em 2003, o Encontro Nacional de Violeiros, que se vem realizando anualmente na cidade de Ribeirão Preto, no interior paulista. A afirmação de que o evento se realiza sob uma imensa figueira de 400 anos reforça a ideia da tradiçāo. Recorrendo às palavras do violeiro Ivan Vilela, a reportagem, no entanto, defende que, antigamente, as manifestaçōes culturais estrangeiras que chegavam ao Brasil não eram totalmente assimiladas, mas se fundiam com o repertório nacional. A própria viola, símbolo da cultura caipira, foi introduzida durante a colonização portuguesa, de acordo com Vilela. Hoje as coisas mudaram:

...está cada vez mais dificil que a mistura aconteça. pois essas referēncias nacionais estāo se perdendo. A missāo de quem procura preservar as raizes culturais brasileiras hoje vai além de uma atitude puramente xenófoba, de negar o que vem de fora. mas sim garantir que nāo haja apenas assimilação, mas uma fusão com nossos elementos. (VIOLAR..., 2006. p. 10)

Assim, o MST se coloca como missão promover e defender a cultura brasileira das invasões externas, o que para os sem-terra é motivo de orgulho (NESTA..., 2004). É preciso ressaltar também que a fusão entre as manifestações culturais estrangeiras e locais nunca foi natural e harmoniosa, mas sempre se deu em um contexto de conflito e negociação, o que ainda é válido nos dias de hoje.

Se, na agricultura, o movimento responde às ameaças externas com novas técnicas de cultivo e organização, na cul- 
tura a resposta se dá pela defesa de elementos tidos como tradicionais e tipicamente brasileiros: uma visão romântica de cultura. Apesar de reconhecer a mescla como constitutiva das manifestaçōes culturais, o movimento se refere a elas como puras e portadoras de uma essência que as diferencia uma da outra em termos de filiação nacional. Como resultado, há um embate que se inscreve no tradicional estilo Nós versus Eles: a típica e pura cultura norte-americana em oposição à típica e pura cultura brasileira. Mas que cultura brasileira é essa que o movimento procura promover? A cultura sertaneja, derivada da indígena e cabocla, que nos remete aos primórdios da fundaçāo do país. Ela se observa nāo apenas na música, mas também na culinária e noutras manifestações artísticas. Durante o Encontro Nacional de Violeiros, é realizada também a Festa do Milho Verde, "repleta de milho cozido, pamonha, bolo de milho e curau" (NESTA..., 2004). O MST utiliza elementos da cultura sertaneja para afirmar sua identidade própria, definindo-o como um movimento brasileiro formado por grupos raciais e sociais marginalizados. Mas também se apropria desses elementos para caracterizá-los como a pura expressão da cultura brasileira em geral. Obviamente não deixa de ser uma manifestação política. $O$ caipira é o que mais se aproxima de ser o outro do estilo country, que, em termos culturais, é uma representação dos adversários do movimento.

Por motivos semelhantes, a cultura popular brasileira esteve também em evidência nas discussões que se seguiram à apresentação, pelo deputado Aldo Rebelo, de um projeto de lei para regulamentar o uso de estrangeirismos no Brasil. O deputado defende que o linguajar do camponês nordestino tem mais legitimidade do que o dos cariocas urbanos que instalaram uma estátua da liberdade em plena Barra da Tijuca. Rajagopalan comenta que o deputado, em nome da defesa do povo, efetua uma uniformização dos diferentes segmentos que o compõem. Os moradores da Barra da Tijuca estariam traindo os verdadeiros interesses da pátria, atuando como agentes 
das forças de globalização. Para o deputado, portanto, "o verdadeiro povo brasileiro seria composto pelos camponeses e não pelos esnobes, desenraizados da verdadeira cultura" (RAJAGOPALAN, 2003, p. 96).

Quanto ao MST, as línguas disponiveis na página da Internet são todas de origem europeia: inglês, espanhol, francês, italiano, sueco, alemão e holandês. Essa opção se explica provavelmente pelo grande número de pessoas que elas atingem no mundo todo, o que fica mais evidente no caso do inglês. São também as línguas dos paises onde há grupos que apoiam as causas dos sem-terra. A atuação desses grupos é um exemplo da ausência de fronteiras fixas entre os chamados paises centrais e periféricos na atualidade. Com relação ao português, o movimento optou por não fazer uso de estrangeirismos em seus documentos, provavelmente como forma de resistência à invasão cultural norte-americana, em sintonia com as propostas do deputado Aldo Rebelo. Mas o português não deixa de ser também a língua do invasor, ainda que em outras épocas. Se houve uma mescla entre elementos portugueses, indígenas e africanos na música e na culinária, entre outras manifestações culturais, na língua a assimilação foi quase completa. O português se impôs como língua oficial, tomando de empréstimo apenas alguns poucos elementos das línguas indígenas e africanas. Além disso, a norma utilizada é a culta, que em tese não reflete a identidade dos sem-terra. Entretanto, a exemplo do inglês e das novas tecnologias, a norma culta do português possibilita a adoção ou elaboração de práticas discursivas que dão acesso ao poder ou se constituem como resistência ao poder constituído.

Já foi mencionado anteriormente que o MST procura se articular com outros movimentos sociais que tenham pelo menos uma causa em comum: a luta contra a opressão de poderes hegemônicos e totalizantes. Essa luta pode ter uma dimensão tanto local quanto global, dependendo de quais atores estejam envolvidos. No entanto, há uma aparente contradição quando o movimento adota um discurso nacionalista e 
promove uma variante particular de cultura, baseada na tradição, com o objetivo de universalizá-la, pelo menos em território nacional. Construir identidades diferenciais com um total isolamento em relação ao mundo exterior não é, para Laclau (1996, p. 29), uma alternativa política viável, pois a preservação de identidades puras pode ser usada como desculpa para a consolidação de formas de subordinação e exclusão. Laclau aponta que o oprimido nāo pode afirmar sua identidade sem afirmar também a do opressor: a diferença que os define é um componente essencial da identidade do oprimido. Nesse caso, é importante a ideia de que uma identidade não pode ser definida sem se contrastá-la com seu contexto. Ao se fazer a diferenciação, também o contexto é definido. O oposto também é válido: "não posso destruir um contexto sem destruir, ao mesmo tempo, a identidade do sujeito particular que efetua a destruição" (LACLAU, 1996, p. 27).

Por essa razão, um movimento social não se define pelas suas qualidades particulares e intrinsecas, mas pelas relações de poder que caracterizam o contexto em que ele está inserido. Transformadas essas relações, modifica-se também sua identidade. No atual contexto da globalização hegemônica, a música e a culinária caipiras promovidas pelo MST adquirem significado principalmente em contraste com o estilo country norte-americano. O mesmo se aplica à oposição entre a língua portuguesa e a inglesa. São contra-narrativas, fazendo frente a uma narrativa canônica dominante. Se houver uma mudança nessa relação, os significados também mudarão. No entanto, quando o MST lança mão de discursos puristas para afirmar sua identidade, ele está negando as próprias relaçōes de poder existentes entre os grupos sociais.

A identidade nacional que o movimento deseja promover assume as particularidades definidoras do sem-terra, como se fossem próprias de uma essencialidade inerente. $O$ problema com essa postura é que, segundo Laclau (1996, p. 27), "se a particularidade se afirma como mera particularidade, numa relação puramente diferencial com outras particularidades, ela 
está sancionando o "status quo" na relaçāo de poder entre os grupos" Se a diferença é colocada como algo essencial, então qualquer particularidade está apta a se tornar universal. Como a do Movimento Tradicionalista Gaúcho (MTG), cujo objetivo principal é defender e promover a chamada cultura gaúcha não apenas como uma manifestação regional, mas também como tipicamente brasileira (OLIVEN, 1992). Esse movimento busca também resgatar muito da cultura indígena local e defender o que ele acredita serem os costumes do campo, a exemplo do MST Entretanto, seus fundadores eram filhos de latifundiários e membros da classe média urbana, e não trabalhadores rurais sem terra. O que o MTG faz, na verdade, é inventar uma tradição camponesa que, no seu entender, representa o "verdadeiro" gaúcho como uma das manifestações culturais brasileiras mais tipicas. Esses são aspectos que não podem ser levados em consideração se as particularidades forem tratadas como essenciais, fora do contexto onde se dão as relações de poder.

\section{Consideraçōes Finais}

Ao eleger o rural e o sertanejo como definidores da cultura nacional, o MST pode estar excluindo parceiros que não se encaixam nessa categoria, principalmente os de base urbana. Por um lado, o movimento se alia a grupos sociais para lutar por causas em comum, mas por outro os exclui pela própria diferença. No entanto, em contraste com as visões essencialistas que o MST tem de cultura brasileira, existe uma parceria entre os sem-terra e o Movimento Hip Hop (TONI C, 2006, p. 36), que é urbano e influenciado por elementos culturais norte-americanos. Diferentemente do country, o hip hop é uma expressão cultural fortemente identificada com as minorias raciais e sociais que vivem nas periferias das grandes cidades. Nesse caso, ao invés da identidade de "tradição" que tenta recuperar uma "pureza anterior" - é a identidade de "tradução" - sujeita "ao plano da História, da Política, da re- 
presentação e da diferença" (HALL, 2003, p. 87) - que volta a predominar. $\mathrm{O}$ movimento narrativo duplo em que se inscreve o MST evidencia a sutileza das fronteiras que delimitam as questōes culturais. "Todo ato cultural vive essencialmente nas fronteiras”, diz Bakhtin (1990, p. 274). Por essa razão, os pontos nodais que formam uma rede social são mais eficazes quando produzem identidades novas e dinâmicas e não quando afirmam particularidades estáticas, separadas do contexto conflituoso da articulação.

Ao transcender sua identidade de resistência (CASTELLS, 1999b, p. 24) ou de tradição (HALL, 2003, p. 87), o MST se expande para abarcar a luta global de parceiros nacionais e internacionais contra um inimigo comum, multidimensional e onipresente, assumindo uma identidade de projeto (CASTELLS, 1999b, p. 24) ou de tradução (HALL, 2003, p. 87). Dessa forma, o movimento garante também seu direito de narrar, e de construir sua identidade, não como agente individual, mas como parte de "toda uma rede discursiva, cultural, política le] institucional” (BHABHA, 2001). A dimensão nacional versus a estrangeira perde sua força diante dos novos desdobramentos das relações de poder em escala global. Se os adversários estão aqui dentro e lá fora, os aliados também. Fiorin (2002, p. 122), ao discutir a polêmica sobre o uso de estrangeirismos no Brasil, afirma que "a esquerda é internacionalista. Deve contrapor o internacionalismo proletário ao internacionalismo burguês" Mas ainda se está a incorrer numa oposição binária. Talvez seja mais adequado fazer uso do termo "transnacional popular" (YUDICE, 2004, p. 300) em vez de "internacionalismo proletário" capaz de contemplar ambas as identidades de resistência e de projeto do MST tanto na sua ação quanto na sua auto-representação. 


\section{BIBLIOGRAFIA:}

BAKHTIN, M. Questóes de literatura e estética: a teoria do romance. (Trad. Aurora Fornoni Bernardini et alii.) São Paulo: Unesp/Hucitec. 1988. pp. 71-210.

The problem of content, material, and form in verbal art. In: BAKHTIN, Mikhail. Art and answerability: early philosophical essays. (Ed. Michael Holquist e Vadim Liapunov. Trad. Kenneth Brostrom). Austin: University of Texas Press, 1990. pp. 257-325.

BHABHA, H. O local da cultura. (Trad. Myriam Ávila, Eliana L.L. Reis e Gláucia R. Gonçalves). Belo Horizonte: UFMG, 1998.

BRUNER, Jerome. Acts of meaning. Cambridge: Harvard University Press, 1990.

CASTELLS, Manuel. A sociedade em rede. (Trad. Roneide V. Majer). 2. ed. São Paulo: Paz e Terra, 1999a.

CASTELLS, Manuel. O poder da identidade. Trad. Klauss Brandini Gerhardt. São Paulo: Paz e Terra, 1999b.

FIORIN, J. L. Considerações em torno do projeto de lei $n^{\circ}$ 1676/99. In: FARACO, Carlos A. (Org.) Estrangeirismos: guerras em torno da língua. 2. ed. São Paulo: Parábola, 2002. p. 107-125.

GOHN, Maria da Glória. Apresentação. In: SOUZA, Maria Antônia de. Educação e cooperação nos assentamentos do MST. Ponta Grossa: UEPG, 2006. p. 9-12.

GRAMSCI, Antonio. Cadernos do cárcere. Trad. Carlos N. Coutinho. Rio de Janeiro: Civilização Brasileira, 2000. v. 2

HALL, Stuart. A identidade cultural na pós-modernidade. 7. ed. Trad. Tomaz T. da Silva e Guacira L. Louro. Rio de Janeiro: DP\&A, 2003. JORNAL SEM TERRA, São Paulo, n. 267 p. 10, nov. 2006.

LACLAU, E. Universalism, particularism and the question of identity. In: LACLAU, Ernesto. Emancipations. London/New York: 1996. p. 20-35.

Nuevas reflexiones sobre la revolución de nuestro tiempo. 2. ed. Buenos Aires: Nueva Visión, 2000.

MENEZES DE SOUZA, L. M. Hibridismo e tradução cultural em Bhabha. In: ABDALA JUNIOR, Benjamin (Org.). Margens da cultura: mestiçagem, hibridismo \& outras misturas. Sảo Paulo: Boitempo. 2004. p. 113-133.

MOUFFE, C. Feminism, citizenship, and radical democratic politics. In: NICHOLSON, Linda; SEIDMAN, Steven (Eds.). Social 
postmodernism: beyond identity politics. Cambridge/New York: Cambridge, 1995. p. 315-331.

OLIVEN, R. G. A parte e o todo: a diversidade cultural no Brasil-nação. Petrópolis: Vozes, 1992.

PATTON, C. Refiguring social space. In: NICHOLSON, Linda; SEIDMAN, Steven (Eds.). Social postmodernism: beyond identity politics. Cambridge/New York: Cambridge, 1995. p. 216-249.

RAJAGOPALAN, K. Por uma linguistica crítica. Sāo Paulo: Parábola, 2003.

RICOEUR, P. Teoria da interpretaçāo. Trad. Artur Morão. Lisboa: Ediçōes 70, 1976.

TONI C. O fim do MST. Revista Sem Terra. São Paulo, n. 36, p. 36, nov.-dez. 2006.

YÚDICE, George. A conveniência da cultura: usos da cultura na era global. Trad. Marie-Anne Kremer. Belo Horizonte: UFMG, 2004.

\section{FONTES ELETRÔNICAS:}

A reforma agrária $e$ o povo brasileiro. 28 mai. 2005. (In http:// www.midiaindependente.org/eo/blue/2005/05/317658.shtml.) Acesso em 10 de agosto de 2007

Campanha pela demarcação das terras indigenas. 9 fev. 2007 Disponivel em http://www.mst.org.br/mst/pagina.php?cd=2775. Acesso em 10 de agosto de 2007

Communications Sector. Disponivel em: http://www.mstbrazil.org/ ?q=book/print/16. Acesso em 23 de dezembro de 2006.

Encontro de Violeiros, Tribunal dos Transgénicos e Campanha Nacional pelo Trabalho. 19 mar. 2004. Disponivel em http://www.mst.org.br/ mst/pagina.php?cd=181 . Acesso em 29 de janeiro de 2007

Entrevista: Marina dos Santos. Entrevistador: Marcelo Salles. Disponivel em: http://www.fazendomedia.com/novas/ entrevista081206.htm. Acesso em 27 de dezembro de 2006.

History of MST slogans. Disponivel em: http://www.mstbrazil.org/ ?q=book/print/16. Acesso em 23 de dezembro de 2006.

Mulher sem terra na luta pela reforma agrária. 25 ago. 2006. Disponivel em: http://www.mst.org.br/mst/pagina.php?cd=1875. Acesso em 29 de maio de 2007 
The right to narrate: interview with Homi Bhabha. (Entrevistador: Kerry Chance. 19 mar. 2001. Disponivel em http://hrp.bard.edu/ resource pdfs/chance.hbhabha.pdf. Acesso em 8 de agosto de 2007 Who are the landless or sem-terra? Disponivel em http:// www.mstbrazil.org/?q=book/print/16. Acesso em 23 de dezembro de 2006.

ABSTRACT: This paper seeks to examine the role of narrative in the identity construction of the landless worker. The narrating process implies the possibility of constructing an identity for oneself. As for the landless movement, narrative is useful as a tool for portraying - for the landless themselves and society as a whole - an image other than that presented by dominant groups. usually conceived of as their opponents. Such a counter-narrative is constitutive of both the landless's selfrepresentation and their actions. As a result, the identity which the movement seeks to construct for itself can be based both on attributes taken from tradition - thus reinforcing purist notions - as well as on difference. The movement's attitudes towards linguistic and cultural expressions are an important part of this analysis. The data are based on printed and electronic texts produced by the MST.

Keywords: narrative; identity; loanwords; culture 